\title{
Research on the Consumer Purchase Intention for the C2B Customization of Fruits and Vegetables Based on the Supply-side Reform
}

\author{
Xin CUI* \\ Business School of Shandong University at Weihai, \\ Weihai, China \\ e-mail: chlgms@sdu.edu.cn \\ *Corresponding author
}

\author{
Lichen WANG \\ Depart. of Accounting, Business School of Shandong \\ Univ. at Weihai, Weihai, China \\ e-mail:wanglichen19960812@163.com
}

\begin{abstract}
The supply-side reform has become the inevitable requirement of China's economy into the new normality. Along with the development of the supply-side reform, the C2B (Consumer to Business) customization of fruits and vegetables based on agricultural Internet plus will gradually become the new model of agricultural sales in the future. Based on the study of the interviews with the businessmen and the relevant reference, this paper builds a TAM (Technology Acceptance Model) to analysis the factors that influence the consumers purchase intention for the $C 2 B$ customization of fruits and vegetables. The factors are verified by the questionnaire and the SPSS (Statistical Product and Service Solutions) analysis. The results show that the C2B customization pattern is still in the primary stage of its development. Perceived usefulness, perceived superiority of products and purchasing power have prominent positive effects on the consumer purchase intention, which can provide important guiding significance to the development of the $\mathrm{C} 2 \mathrm{~B}$ customization of fruits and vegetables.
\end{abstract}

Keywords-Consumer Purchase Intention; C2B Customization; Supply-side Reform

\section{INTRODUCTION}

As traditional sellers' market fails to meet the needs of all customers, the $\mathrm{C} 2 \mathrm{~B}$ (Consumer to Business) customization come into being [1]. $\mathrm{C} 2 \mathrm{~B}$ is a personalized mode of service which emphasizes producing different products to meet the needs of different customers' services. During the process, the private demand of the customers will be satisfied by participating in the selection or design of the products, which requires relying on the Internet in actual operation process of the C2B customization [2]. This is also applicable to the agricultural products which closely related to the life.

There are few empirical studies in this pattern because the $\mathrm{C} 2 \mathrm{~B}$ customization of fruits and vegetables is very prospective. In the TAM (Technology Acceptance Model) of Davis (1986), perceived ease of use and perceived usefulness have important effect on consumer behavioral intentions [3]. In addition, Balasubramanian (2001) proposed that the values of customers had a great impact on their choice [4]. The model of McKnight (2002) showed that the business reputation and website security influence customers' initial trust. Website with high reputation can lead to transaction more easily [5]. Zhang Zhi Hong (2010) found that the consumers' preferences about the C2B customization can directly influence their attitude, and therefore affect the commercial activity with custom service [6]. Saigiraf (2016) demonstrated that perceived ease of use and other factors positively affect the buyers' willingness [7]. As for the fruits and vegetables agricultural products, Zhou Wang (2014) put forward that traditional online sales about agricultural products' supply chain is not transparent enough and C2B customization can solve this problem effectively [8].

\section{MAJOR HEADINGS}

Through the interviews with the businessmen and the relevant reference, many factors are found which influence the customers' attitude. After selecting, some factors are added into the model such as the perceived usefulness (PU), perceived ease of use (PE), perceived risk (PR), online shopping experience (OS) and customer behavior intention (CB). What's more, considering the characteristic of $\mathrm{C} 2 \mathrm{~B}$ customization, the following two factors are also added into the model. They are the purchasing power (PP) and perceived superiority of products (PO) [9].

As TAM can explore customer acceptance of new technologies, it can be built to analysis the factors which influence the customers' attitude of the C2B customization of fruits and vegetables [10]. Based on the modified TAM, this paper tries to ensure the accuracy of the analysis. Fig. 1 is the preliminary model.

Through the research and analysis, the following assumptions are given here at first and then it will be judged which of them are held while the others are not supported in the next section.

H1: PU positively affects CB. H2: PE positively affects $\mathrm{CB}$.

H3: PE positively affects PU. H4: PR negatively affects $\mathrm{CB}$.

H5: PO positively affects CB. H6: PP positively affects PU.

H7: PP positively affects PE. H8: PP positively affects PO.

H9: PP positively affects CB. H10: OS positively affects PE.

H11: OS negatively affects PR. H12: OS positively affects CB. 


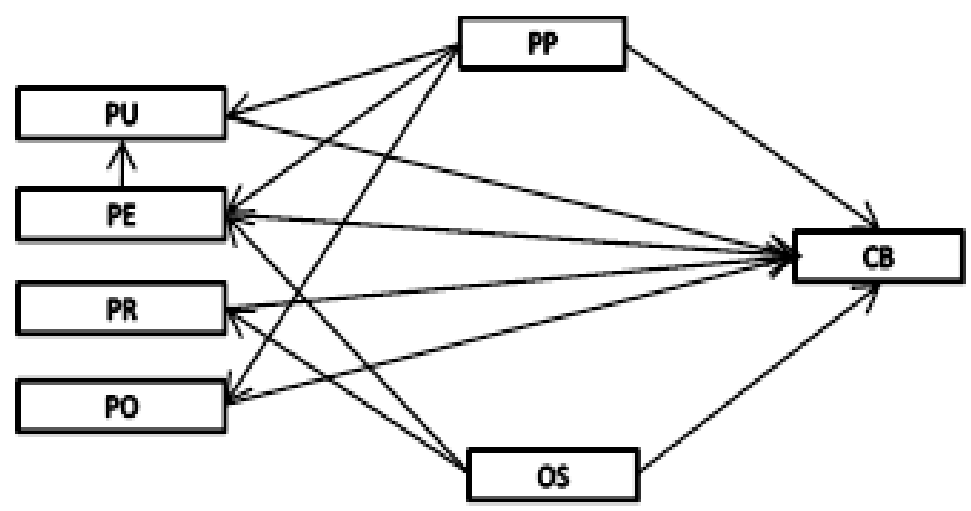

Figure 1. TAM of the consumer purchase intention for the $\mathrm{C} 2 \mathrm{~B}$ customization of fruits and vegetables

\section{QUESTIONNAIRES AND STATISTICAL ANALYSIS}

The design of the questionnaire is referred to the previous studies and some innovative designs about the $\mathrm{C} 2 \mathrm{~B}$ customization of fruits and vegetables are also considered. No less than three indicators are set for each factor. The questionnaire consists of two parts: questions about the demographic variables and the Likert scale. The questionnaires were sent out in a small area. After analyzing, the reliability and validity of the questionnaire are excellent. Then, totally 470 questionnaires were sent out, while 464 valid ones were got back after removing the unqualified ones. Before the statistical analysis, the demographic variables are analyzed at first. The results show that the sample selection meets the requirements of equilibrium, comprehensive and random.

\section{A. Reliability Analysis}

The reliability of the questionnaire is measured by SPSS (Statistical Product and Service Solutions). There are 7 factors in the questionnaire and each factor includes 3-5 indexes. Each factor's reliability is tested. According to the theory of Nunnally, Cronbach's Alpha values are greater than 0.7 that can prove high reliability. The Cronbach's Alpha of this questionnaire's factors are all greater than 0.7 . The holistic rating scale's Cronbach's Alpha is 0.876 , which indicates that the reliability of the questionnaire is quite high and the design is reasonable.

\section{B. Validity Analysis}

Firstly, the questionnaire is tested by $\mathrm{KMO}$ (Kaiser-Meyer-Olkin) test and Bartlett test of sphericity, and KMO value (0.807) is obtained. The factor analysis method is suitable when KMO between 0.8 and 0.9 , so this method can be used to analyze the questionnaire. Secondly, select factors whose eigenvalue is greater than
1 on the basis of component factor analysis. Finally, rotate it with maximum variance method. The component matrix after rotating is shown in Table 1 . In order to make the result significant, it is canceled to display the coefficients which are less than 0.5. From Table 1, the coefficients of the indexes in their factors are greater than 0.5 and the indexes values are high. At the same time, the coefficients of the indexes of other factors are lower than 0.5. After processed, it can be seen that the convergent validity and discriminant validity of the questionnaire is high, which means that the questionnaire is reasonable designed.

\section{Correlation Analysis}

The correlation analysis is used to analysis the correlation among the variables. $\mathrm{H} 1, \mathrm{H} 3, \mathrm{H} 4, \mathrm{H} 5, \mathrm{H} 6, \mathrm{H} 7$, $\mathrm{H} 8, \mathrm{H} 9, \mathrm{H} 10$ and $\mathrm{H} 12$ are proved to be valid based on the strong correlation among the factors. As the Poisson's ratio between the factors OS and RIS is just 0.029 , which means that is not obvious, H11 is not supported.

\section{Regression Analysis}

To further explore the relationship among the factors, the method of multiple stepwise regression analysis is adopted. The result is shown in Table 2 . By analyzing the regression of $\mathrm{PU}$, the swelling index of $\mathrm{PE}$ and $\mathrm{PP}$ is 0.000 , which means there is a linear relationship between $\mathrm{PE}$ and $\mathrm{PP}$ at the 0.05 level of significance, and $\mathrm{PU}=0.336 * \mathrm{PE}+0.171 * \mathrm{PP} . \quad$ Similarly, $\quad \mathrm{PE}=$ $0.251 * \mathrm{OS}+0.168 * \mathrm{PP}, \quad \mathrm{PO}=0.287 * \mathrm{PP}$, $\mathrm{CB}=0.256 * \mathrm{PU}+0.381 * \mathrm{PO}+0.095 * \mathrm{PP}$.

In summary, the assumptions such as $\mathrm{H} 2, \mathrm{H} 4, \mathrm{H} 11$ and $\mathrm{H} 12$ are not supported while the others are supported. Based on the above analysis, the model is adjusted and the final modal is obtained, which is shown in Fig. 2. 
TABLE I. FACTOR MATRIX AFTER ROTATING WITH MAXIMUM VARIANCE METHOD

\begin{tabular}{|c|c|c|c|c|c|c|c|}
\hline \multirow{2}{*}{ Code } & \multicolumn{7}{|c|}{ Component } \\
\hline & OS & PP & $\mathrm{PO}$ & $\mathrm{PU}$ & $\mathrm{CB}$ & $\mathrm{PR}$ & $\mathrm{PE}$ \\
\hline OS2 & .810 & & & & & & \\
\hline OS1 & .780 & & & & & & \\
\hline OS3 & .641 & & & & & & \\
\hline OS4 & .632 & & & & & & \\
\hline OS5 & .623 & & & & & & \\
\hline PP4 & & .712 & & & & & \\
\hline PP2 & & .773 & & & & & \\
\hline PP1 & & .698 & & & & & \\
\hline PP3 & & .624 & & & & & \\
\hline PO1 & & & .825 & & & & \\
\hline $\mathrm{PO} 2$ & & & .678 & & & & \\
\hline PO3 & & & .798 & & & & \\
\hline PO4 & & & .551 & & & & \\
\hline PU1 & & & & .813 & & & \\
\hline PU3 & & & & .756 & & & \\
\hline PU2 & & & & .623 & & & \\
\hline PU4 & & & & .567 & & & \\
\hline CB2 & & & & & .734 & & \\
\hline CB1 & & & & & .767 & & \\
\hline CB3 & & & & & .601 & & \\
\hline PR3 & & & & & & .945 & \\
\hline PR1 & & & & & & .923 & \\
\hline PR2 & & & & & & .578 & \\
\hline PE1 & & & & & & & .745 \\
\hline PE2 & & & & & & & .623 \\
\hline PE3 & & & & & & & .698 \\
\hline
\end{tabular}

TABLE II. SUMMARY OF THE REGRESSION ANALYSIS

\begin{tabular}{|l|l|l|l|l|}
\hline $\begin{array}{l}\text { Dependent } \\
\text { variable }\end{array}$ & $\begin{array}{l}\text { Independent } \\
\text { variable }\end{array}$ & $\begin{array}{l}\text { Significance } \\
\text { level }\end{array}$ & $\begin{array}{l}\text { Original } \\
\text { regression } \\
\text { coefficient }\end{array}$ & $\begin{array}{l}\text { Standardized } \\
\text { regression coefficient }\end{array}$ \\
\hline \multirow{2}{*}{ PU } & PE & 0.000 & 0.305 & 0.336 \\
\cline { 2 - 5 } & PP & 0.000 & 0.192 & 0.171 \\
\hline \multirow{3}{*}{ PE } & OS & 0.000 & 0.318 & 0.251 \\
\cline { 2 - 5 } & PP & 0.000 & 0.209 & 0.168 \\
\hline PO & PP & 0.000 & 0.248 & 0.287 \\
\hline \multirow{5}{*}{ CB } & PU & 0.000 & 0.239 & 0.256 \\
\cline { 2 - 5 } & PO & 0.000 & 0.443 & 0.381 \\
\cline { 2 - 5 } & PP & 0.023 & 0.042 & 0.095 \\
\cline { 2 - 5 } & PE & 0.188 & & \\
\cline { 2 - 5 } & PR & 0.246 & & \\
\cline { 2 - 5 } & OS & 0.363 & & \\
\hline
\end{tabular}

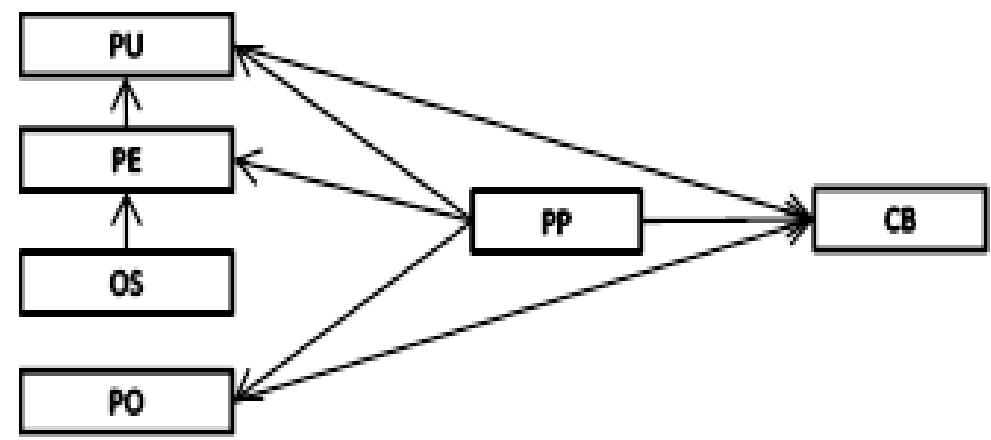

Figure 2. Corrected model of the consumer purchase intention for $\mathrm{C} 2 \mathrm{~B}$ customization 


\section{CONCLUSION}

This paper mainly tests the consumer purchase intention for the $\mathrm{C} 2 \mathrm{~B}$ customization of fruits and vegetables, builds the model and corrects it by empirical analysis. From the results, PU, PP and PO all have some effects on $\mathrm{CB}$, which can be used as reference to the development of $\mathrm{C} 2 \mathrm{~B}$ customization of fruits and vegetables. It's an emerging business and will be conducive to meet the needs of consumers and respond to the call for the supply-side reform.

\section{REFERENCES}

[1] B. Dan, K. W. Zheng, M. L. Liu, B. J. Shao, Study on C2B Business Model of "Internet Plus" Fresh Agricultural Product Supply Chain Based on the Social-nomics, Journal of Business Economics. 8 (2016) 16-23.

[2] Matt Murphy, Mary Meeker, Top mobile internet trends, KPCB Relationship Capital. 2 (2011) 2-5

[3] Davis, A Document Preparation System, second ed., Reading, MA, 1994
[4] S. Balasubramanian, V. Mahajan, The Economic Leverage of the Virtual Community, International Journal of Electronic Commerce. 5 (2001) 103-138.

[5] D. H. Mcknight, V. Choudhury, C. Kacmar, Developing and Validating Trust Measures for e-Commerce: An Integrative Typology, Information Systems Research. 13 (2002) 334-359.

[6] Z. H. Zhang, Strategic Analysis of C2B Based Intelligent E-commerce Model, Soft Science, 2010.

[7] Saigiraf, Kang Yao Wu, Yu Miao, The Influence of Buyer Interaction on Purchase Intention in Electronic Commerce, Journal of Commercial Economics. 9 (2016) 82-84.

[8] Wang Zhou, Yinqiong Zhang, Pengfei Li, Research on the Application of O2O E-Commerce in the New Rural Agricultural Construction of HuNan Province, Computer Knowledge \& Technology, 2014.

[9] Mu Du, Xiangpei Hu, Kuanjiu Zhou, Zhanliang He, IoT-based Farm-to-door Delivery System for Fruit and Vegetable Online Retail, Journal of Systems Engineering. 4 (2014) 215-222.

[10] Jianjun Sun, Ying Cheng, Qing Ke, Advances of Research on Technology Acceptance Model-Meta-analysis, Information Science. 8 (2007) 1121-1127. 